\title{
A general model for the estimation of societal costs of lost production and informal care in Italy
}

\author{
Lorenzo Pradelli ${ }^{1}$, Gianni Ghetti ${ }^{1}$ \\ AdRes HE\&OR, Turin, Italy
}

\begin{abstract}
We developed a general model for estimating and comparing disease- and treatment-specific lost paid/unpaid production (due to premature death and reduced ability) and informal care received (due to reduced ability) in Italy, starting from survival, demographic and Health-Related Quality of Life (HRQoL) data. Assuming the disease is not selecting a systematically different population in terms of mean wage than the general public, age- and gender-specific yearly production values are estimated combining data from the last Italian Time-Use-Survey on time dedicated to paid and unpaid (household, caring and volunteering) activities, with a) the last Italian Wage-Structure-Survey, for paid activities (Human Capital approach), and b) market prices for an equivalent service, for unpaid production (Proxy Good approach). To avoid double counting, age- and gender-specific maximum care needs are approximated with time dedicated to eating and personal care, reported in TUS. Present monetary values of future productivity and informal care are estimated applying a $3.5 \%$ annual discount rate. Lost life years due to a particular condition/treatment are estimated by comparison of its survival curve with the corresponding age- and gender-normalized survival curve of the general Italian population. The degrees of reduced productivity and need for informal care for remaining life years are estimated by comparison of condition-/treatment-specific reported HRQoL data with demographically matched Italian norms. Our results will be useful for cost-effectiveness and budget impact analyses conducted from the perspective of the Italian society and we encourage the inclusion of these costs in economic evaluations to allow decision makers to be fully informed about the costs and consequences of their decisions on healthcare interventions.
\end{abstract}

\section{Keywords}

Indirect cost; Health-Related Quality of Life; Societal perspective; Yearly production value

\section{INTRODUCTION}

\section{Italian background}

In Italy, pharmaceutical companies have been required to provide economic evaluations when applying for pricing and reimbursement negotiations since 1997 [1]. As occurs in most European Union countries, almost all recently commercialized drugs in Italy come from the Centralized Approval Procedure, where the European Medicines Agency (EMA) must decide if a product constitutes a significant innovation in order to be evaluated. In a health care system such as the Italian one, based on a National Health Service that provides most drugs free of charge to its citizens, pricing negotiations with the regulatory authorities take place when the product is filed for reimbursement. The phar- maceutical company is called upon to present in-depth documentation for the new drug on all relevant aspects, among which economic evaluation.

\section{Direct costs}

The economic costs of disease can be divided into direct, indirect, and intangible costs [2]. From a societal perspective, direct costs are the value of resources used to prevent, detect, and treat a health impairment or its effects [3]. These costs encompass both healthcare and non-healthcare costs: the former are defined as the medical expenditures for diagnosis, treatment, and rehabilitation, etc.; while the latter, borne by the patient and his/ her family, are related to the consumption of non-healthcare resources like transportation, household expenditures, relocating, property losses, and informal cares of any kinds [4].
Corresponding author Lorenzo Pradelli

I.pradelli@adreshe.com

\section{Disclosure}

The authors have no conflicts of interest to declare. 


\section{Informal care}

Informal care constitutes a substantial part of the total care received by (especially chronically ill) patients and elderly in many countries $[5,6]$. Informal care can complement and substitute the formal care patients receive. It can complement formal care, for example, when informal caregivers assist patients with the management of their disease or medication. This improves the overall quality of care for patients who are not fully independent (e.g., in the context of aging, dementia, mental illness) [7,8]. Informal care can also substitute formal care by supporting patients to stay at home longer or to be discharged from formal care sooner [9-11].

When performing an economic evaluation in health care, ignoring informal care is problematic, because it may result in biased calculations of cost effectiveness and, hence, in wrong policy information and decisions. In Krol et al. [12], for instance, the large impact that ignoring productivity costs can have on the outcomes of evaluations is highlighted: including them changes the main conclusion on the cost-effectiveness of the technology being considered. Ignoring the costs and effects of informal care may have similar impacts, especially in the context of disease areas where informal care is relatively important, such as in the case of Alzheimer's disease or rheumatoid arthritis. For a thorough discussion on this subject refer to van den Berg et al. [13].

An informal caregiver can be defined as a person who provides care and support to a family member, friend, or acquaintance with a chronic illness, disability, or other long-lasting care need due to ill health or aging [14]. Two main types of costs of informal care can be distinguished:

1. Out-of-pocket expenses, such as travel expenses;

2. Time dedicated to caring (the major component).

In general, informal care activities can be distinguished in three categories:

1. Household work: such as cleaning, cooking, groceries shopping and other chores around the house;

2. Personal care: such as dressing, washing, combing, feeding, and medicating;

3. Practical support: such as moving outside the house, going to the physician and taking care of daily duties (e.g. going to the post office).

\section{Indirect costs}

Indirect costs comprise the value of production lost to society due to absence from work, reduced ability, and death of productive people, for both paid and unpaid activities [3].
Since indirect costs do not directly influence expenditures for treating the underlying disease, they are not easily measurable. However, indirect costs often strongly influence the result of economic evaluations of health care programs as shown in Krol et al. [12].

\section{Intangible costs}

Intangible costs relate to the non-monetary consequences that are by definition difficult to measure and assess, such as pain and suffering associated with the disease. Even though these would be duly quantified, they should not be included. Being intangible, costs represented by psychological and physical discomfort associated with the state of the disease, they are usually already adequately measured in effectiveness, for example, by faster healing or decreased side-effects, as well as by greater quality of life (utility) associated with the condition [15].

The number of economic evaluations of pharmaceuticals is rapidly growing, and so is their relevance. In Italy, pharmacoeconomics has gained importance since the National Drug Committee (Commissione Unica del Farmaco) listed this as one of the subjects to be considered in submitting approval dossiers for innovative drugs [16]. Indirect costs and informal care are a considerable part of the economic burden of diseases and should therefore be carefully taken into account.

The Italian guidelines for economic evaluations [4] stress that, in the evaluation carried out from society's point of view, the cost estimates must consider both direct costs (medical and non-medical) and indirect costs. However, in Italy, until a few years ago, studies evaluating indirect costs were only few [17]. With this in mind, we developed a standardized method for estimating and comparing condition- and treatment-specific lost paid and unpaid production (due to premature death and reduced ability) and informal care received (due to reduced ability to cope with every day's tasks), in Italy, starting from survival, demographic and health-related quality of life (HRQoL) data.

\section{METHODS}

\section{Estimating indirect costs}

Productivity losses may occur both in paid and in unpaid work, due to either premature death or reduced ability, or both. According to Capri et al. [15], for the estimation of paid productivity losses the Human Capital approach [18] should be used.

Human Capital approach assumes that the value to society of productivity losses should 


\begin{tabular}{|c|c|c|c|c|c|c|c|c|c|c|c|c|c|c|}
\hline \multicolumn{15}{|c|}{ Time use in daily activity (h.min) } \\
\hline \multirow{2}{*}{$\begin{array}{c}\text { Gender } \\
\text { Age }\end{array}$} & \multicolumn{7}{|c|}{ Male } & \multicolumn{7}{|c|}{ Female } \\
\hline & $3-5$ & $6-10$ & $11-14$ & $15-24$ & $25-44$ & 45-64 & $65+$ & $3-5$ & $6-10$ & $11-14$ & $15-24$ & $25-44$ & 45-64 & $65+$ \\
\hline Eating & 2.00 & 2.00 & 2.00 & 1.53 & 1.57 & 1.58 & 2.11 & 2.00 & 2.00 & 2.00 & 1.52 & 1.51 & 1.54 & 2.00 \\
\hline Caring for oneself & 1.00 & 1.00 & 1.00 & 0.53 & 0.53 & 0.54 & 1.00 & 1.00 & 1.00 & 1.00 & 1.04 & 0.53 & 0.52 & 0.55 \\
\hline Paid work & - & - & - & 1.49 & 5.47 & 4.24 & 0.21 & - & - & - & 1.06 & 2.59 & 2.00 & 0.04 \\
\hline Household activities & 0.13 & 0.15 & 0.19 & 0.17 & 0.39 & 1.19 & 1.53 & 0.11 & 0.26 & 0.38 & 1.06 & 3.20 & 4.42 & 4.31 \\
\hline $\begin{array}{l}\text { Caring for family } \\
\text { members }\end{array}$ & - & - & - & 0.02 & 0.22 & 0.08 & 0.05 & - & - & - & 0.09 & 1.01 & 0.12 & 0.04 \\
\hline Caring for others & - & - & - & 0.01 & 0.03 & 0.06 & 0.10 & - & - & - & 0.03 & 0.05 & 0.14 & 0.11 \\
\hline Volunteering & - & - & - & 0.01 & 0.01 & 0.03 & 0.02 & - & - & - & 0.03 & 0.01 & 0.02 & 0.03 \\
\hline
\end{tabular}

Table I. Daily activities of interest from TUS [20]

be measured as the present value of future lost time, valued according to the market gross wage. Therefore, all the working hours lost because of health impairment and related treatments are valued according to the individual gross income.

Unpaid work is the production of goods and services that are not sold on a conventional market [19]. In Capri et al. [15] it is suggested to use the Proxy Good approach to estimate unpaid productivity losses. With this approach, the monetary value of unpaid work is based on the value of the closest market substitute. Housework, for instance, can be valued using the average price of a professional housekeeper.

\section{Societal cost of premature death}

The last available Italian Time Use Survey - TUS - [20] provides data on how people arrange their daily routine (Table I). Based on these data, the model estimates age- and gender-specific yearly time dedicated to both paid and unpaid activities. These data have been supplemented with Italian age- and gender-specific life expectancies [21].

In order to give a monetary value to paid work, data were taken from the last available Italian Wage Structure Survey [22], providing information on the relationships between the level of remuneration and individual characteristics of employees (sex, age, occupation, length of service, highest educational level attained, etc.) and those of their employer. In particular, it reports gender-specific average hourly gross wage per age-class (Table II).

Under the assumption that the disease is not selecting a systematically different population in terms of mean wage than the general public, our model estimates age- and genderspecific yearly paid production value by combining the above data (Table III).

For what concerns unpaid production, we distinguish three main types of activities:

\begin{tabular}{ccc}
\hline \multirow{2}{*}{ Age-class (years) } & \multicolumn{2}{c}{ Hourly gross wage $(\boldsymbol{\ell} / \mathbf{h})$} \\
\cline { 2 - 3 } & Male & Female \\
\hline $14-19$ & 9.75 & 9.38 \\
$20-29$ & 11.37 & 10.88 \\
$30-39$ & 14.49 & 13.61 \\
$40-49$ & 17.29 & 15.77 \\
$50-59$ & 19.98 & 18.21 \\
$60+$ & 24.80 & 20.85 \\
\hline
\end{tabular}

Table II. Gender-specific average hourly gross wage per age-class

\begin{tabular}{ccc}
\hline \multirow{2}{*}{ Age-class (years) } & \multicolumn{2}{c}{ Paid production value $(\boldsymbol{\epsilon} /$ years $)$} \\
\cline { 2 - 3 } & Male & Female \\
\hline $3-14$ & - & - \\
$15-19$ & 6,465 & 3,766 \\
$20-24$ & 7,539 & 4,368 \\
$25-29$ & 24,001 & 11,847 \\
$30-39$ & 30,587 & 14,820 \\
$40-44$ & 36,498 & 17,172 \\
$45-49$ & 27,768 & 11,512 \\
$50-59$ & 32,088 & 13,293 \\
$60-64$ & 39,829 & 15,221 \\
$65+$ & 3,168 & 507 \\
\hline
\end{tabular}

Table III. Estimated age- and gender-specific yearly paid production value

1. Household work: such as cleaning, cooking, groceries shopping and other chores around the house;

2. Caring, for family members and for others: such as taking care of (grand) children, helping out friends or family with cleaning, shopping or personal care;

3. Volunteer work: such as helping out in a community center or at a sports club.

In order to give a monetary value to both household production and caring production, the model uses the minimum wage for a do- 


\begin{tabular}{ccc}
\hline \multirow{2}{*}{ Age-class (years) } & \multicolumn{2}{c}{$\begin{array}{c}\text { Unpaid production value }- \text { household, caring, } \\
\text { and volunteering activities ( } \mathbf{(} / \text { years) }\end{array}$} \\
\cline { 2 - 3 } & Male & Female \\
\hline $3-5$ & 649 & 549 \\
$6-10$ & 749 & 1,299 \\
$11-14$ & 949 & 1,898 \\
$15-24$ & 1,068 & 4,102 \\
$25-44$ & 3,265 & 13,354 \\
$45-64$ & 4,852 & 15,521 \\
$65+$ & 6,531 & 14,491 \\
\hline
\end{tabular}

Table IV. Estimated age- and gender-specific yearly unpaid production value (household activities, caring activities and volunteering)

mestic worker of level C-Super ${ }^{1}(€ 8.21)$, as defined within the National Collective Bargaining Agreement for Domestic Workers [23].

On the other hand, to estimate the monetary value of volunteering, the hourly gross wage $(€ 11.33)$ has been computed based on the median annual gross wage, weekly hours and working weeks as reported in [24].

With these data, the model estimates age- and gender-specific value of yearly unpaid production (Table IV).

\section{Societal cost of reduced ability}

Age- and gender-specific health benchmark are derived from Szende et al. [25], reporting self-reported population norms for 24 countries, based on the EQ-5D ${ }^{2}$ questionnaire [26]. Given this, the model assumes that every year of life lived "below the norm" determines Societal costs, in terms of both paid and unpaid reduced production and in terms of augmented need of informal care.

In particular, rather than considering the global index value of EQ-5D, the model considers the following two domains:

1. Self-care: asking about the ability to wash or dress by oneself;

2. Usual activities: asking about the ability to perform daily activities (e.g. work, study, leisure activities).

Then the model estimates the health impairment as domain-specific percentage reductions. The underlying assumption is that these reductions are a good proxy, respectively, of the reduced ability to care for oneself (the-

\footnotetext{
Belong to this category domestic workers, possessing specific basic knowledge, both theoretical and technical, related to completing the assigned tasks, able to work with autonomy and responsibility

2 The EQ-5D is a generic preference-based measure where health status is divided into five dimensions (mobility, self-care, usual activities, pain / discomfort and anxiety / depression). It was developed by the EuroQol Group in order to provide a simple, generic measure of health for clinical and economic appraisal
}

refore the need of additional informal care) and of the reduced productivity.

Therefore, the model needs condition/ treatment-specific HRQoL data in order to estimate the Societal cost of reduced ability. Given the difference between the "degree of capability" - as measured, for instance, by the physical functioning and role functioning scales of the EORTC QLQ-C30 questionnaire - of the population under study and the Italian norms - i.e. the disease-/treatment-specific ability impairment, the model estimates age- and gender-specific values of lost production for both paid and unpaid activities.

In order to clarify how the observation of a reduced score on HRQoL is translated to a societal cost of reduced ability suppose that the Italian health norm index for the domain "usual activities" is 80 while that of a population under treatment is 64 . Then, the model assumes that the disease under study brings about a health impairment of $20 \%$ (computed as the relative reduction in the health norm index ). What is important at this stage is that the two health norms are measured on the same scale.

Afterwards, the model assumes that this impairment has the same impact on all the daily activities. Consider paid activities: if on average a person spends 5 hours a day working, a person of the population under study will be able to spend just 4 hours a day working, because of his health impairment. This means that these people would be able to produce $20 \%$ less of the yearly value of paid production. Same holds true for unpaid activities.

This example is simplistic (in the model there are age- and gender- specific values) but the idea is that the value of the health impairment is a good proxy to determine the values of lost production, both paid and unpaid, and therefore to determine the burden the Society has to bear because of the health impairment. Many validated measurements instruments, to collect data about health-related productivity loss, ask respondents to provide information about their productivity during a preceding period, but this can be cumbersome. Our aim here is to provide a practical method that needs the typical data available from clinical studies (e.g. age, sex, survival data and health-related quality of life).

\section{Estimating informal care}

If both costs related to unpaid work and the costs related to informal care are included one needs to be aware of potential double counting [19]. In order to avoid incurring this error, since the model already estimates the value of lost unpaid production due to reduced ability, informal care costs only account 
for the time dedicated by the caregivers to the assistance in feeding and personal care.

To make thing clearer consider the following example. The last available Italian TUS also reports age- and gender-specific daily time spent for eating and personal care (Table I). Thus, if a 63-years-old male spends, on average, 172 minutes a day for eating and personal care, the model assumes that a 63-yearsold male with reduced ability cannot receive more than 172 minutes a day of informal care. Obviously, the time of informal care needed depends on the level of reduced ability: the bigger the health impairment, the more the informal care needed.

In this sense, the estimated average yearly time dedicated to eating and personal care is an upper bound for the hours of informal care a person may need.

In order to give a monetary value to informal care, following the Proxy Good approach, the model uses the minimum wage for a domestic worker of level D-Super ${ }^{3}$ (€ 9.77), as defined within National Collective Bargaining Agreement for Domestic Workers [23].

The model then estimates age- and genderspecific yearly maximum value of informal care one may need (Table V).

Informal care is a cost the society has to bear when someone has a reduced ability. Therefore, the model needs condition/treatmentspecific health-related quality of life data in order to estimate the societal cost of informal care, as shown above for lost production.

3 Belong to this category domestic workers that, possessing the necessary professional qualifications, cover specific job positions with responsibilities, decision-making autonomy and / or coordination

\begin{tabular}{ccc}
\hline & \multicolumn{2}{c}{ Maximum value of informal care needed $(\boldsymbol{\epsilon} /$ year $)$} \\
\hline Age-class (years) & Male & Female \\
\hline $3-14$ & 10,698 & 10,698 \\
$15-24$ & 9,866 & 10,460 \\
$25-44$ & 10,104 & 9,928 \\
$45-64$ & 10,223 & 10,043 \\
$65+$ & 11,352 & 10,410 \\
\hline
\end{tabular}

Table V. Estimated age- and gender-specific yearly maximum value of informal care needed

\section{RESULTS}

\section{Premature death: productivity loss}

On the basis of the estimated yearly paid and unpaid production values (respectively Table III and Table IV) and life expectancies, the model estimates age- and gender-specific present value of future productivity (both paid and unpaid), applying a 3,5\% yearly discount rate. This represents the burden the society has to bear for premature death.

As shown in Figure 1, the overall present value of future productivity (both paid and unpaid) increases with age up to 25 , then decreases more rapidly for men, with values crossing at age 58 .

The model estimates lost life years due to a particular condition/treatment by comparing its survival curve with the corresponding age- and gender-normalized survival curve of the general Italian population [21]. Figure 2 shows an example of this comparison.

For estimating condition-/treatment-specific societal cost of premature death, the model takes into account the "natural mortality" of

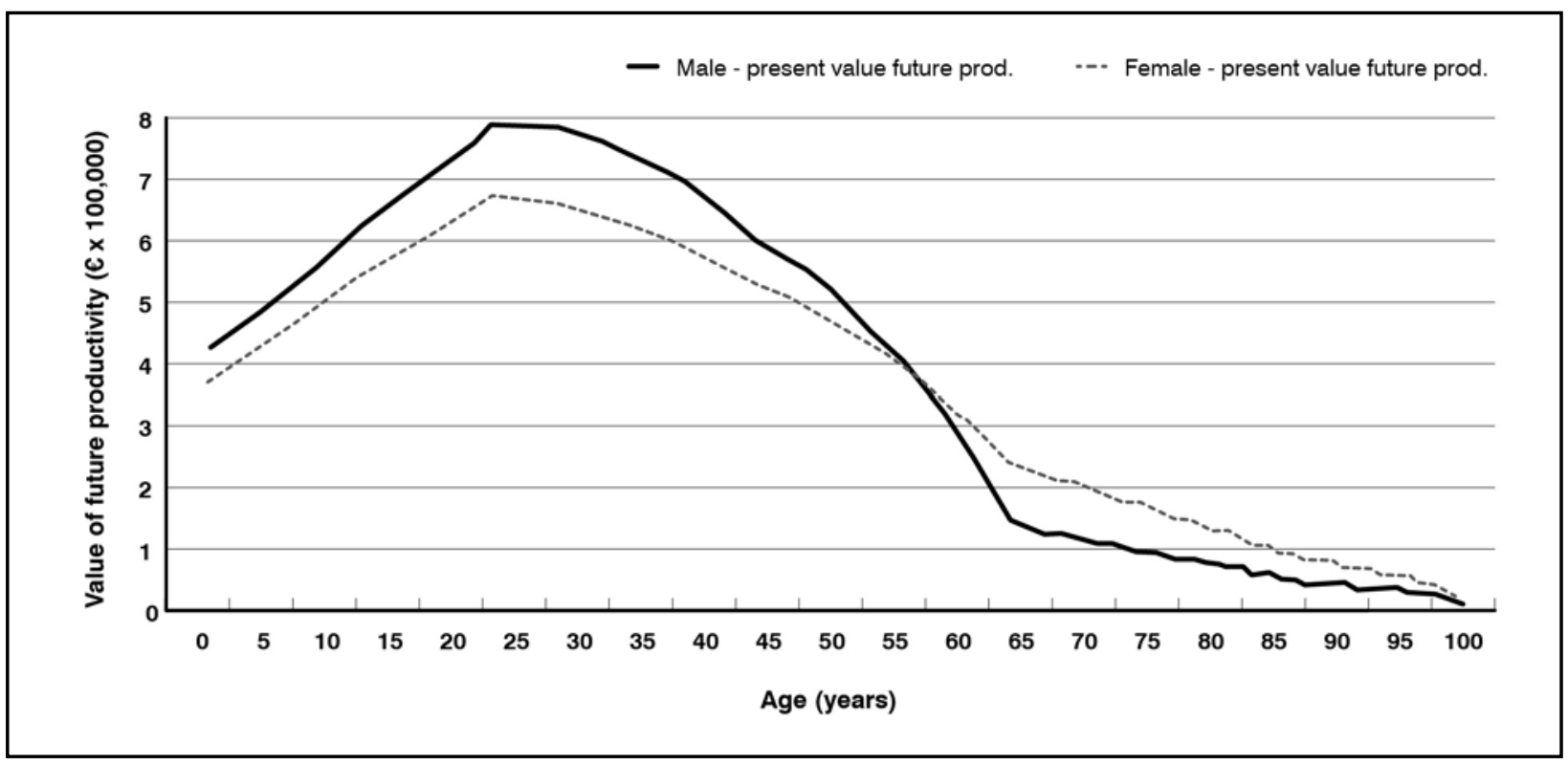

Figure 1. Estimated present value of future productivity (both paid and unpaid) 


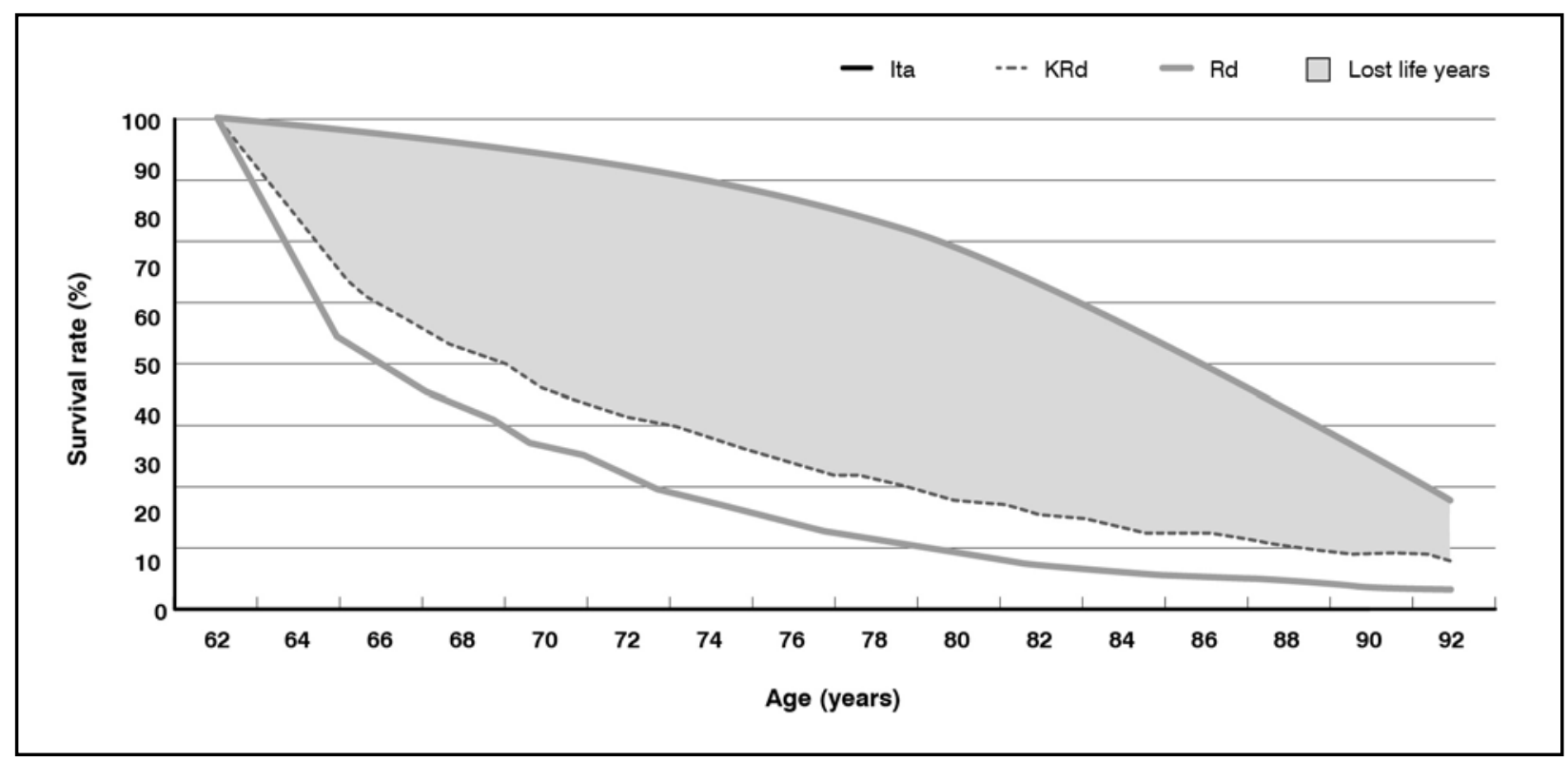

Figure 2. Example of comparison of two condition/treatment-specific survival curves (KRd and Rd in relapsed multiple myeloma patients) with the Italian population survival curve

Ita = Italian population; KRd = carfilzomib with lenalidomide and dexamethasone; $\mathrm{Rd}=$ lenalidomide and dexamethasone

Italian population. Thus, the cost of premature death has to be interpreted as the incremental burden for society due to premature death for the specific condition/treatment.

\section{Reduced ability: productivity loss and informal care}

The model estimates age- and gender-specific yearly values of lost productivity and need for informal care due to reduced ability by comparing condition-/treatment-specific HRQoL data with demographically matched Italian norms.

In order to make things clearer, consider the following application of the methodology developed.

In the ASPIRE trial [27], a randomized, open-label, phase 3 trial, which evaluated the efficacy and safety of carfilzomib with lenalidomide and dexamethasone (KRd) versus lenalidomide and dexamethasone $(\mathrm{Rd})$ in relapsed multiple myeloma patients, HLQoL

\begin{tabular}{ccccc}
\hline \multirow{2}{*}{$\begin{array}{c}\text { Age-class } \\
\text { (years) }\end{array}$} & \multicolumn{2}{c|}{ "Self-care" domain } & \multicolumn{2}{c}{ "Usual activities" domain } \\
\cline { 2 - 5 } & Male & Female & Male & Female \\
\hline $3-24$ & 99.75 & 99.55 & 98.76 & 98.88 \\
$25-34$ & 99.45 & 99.44 & 98.35 & 98.55 \\
$35-44$ & 99.79 & 99.90 & 99.05 & 98.65 \\
$45-54$ & 99.65 & 98.52 & 97.70 & 95.11 \\
$55-64$ & 97.44 & 97.66 & 94.60 & 92.15 \\
$65-74$ & 97.80 & 93.93 & 91.94 & 86.64 \\
$75+$ & 92.48 & 85.22 & 80.83 & 71.51 \\
\hline
\end{tabular}

Table VI. Estimates of age- and gender-specific Italian population norms for what concerns "self-care" and "usual activities" domains was measured using the EORTC QLQ-C30 [28], a validated instrument in this patient population [29-31] that has been widely used in clinical trials of multiple myeloma.

The EORTC QLQ-C30 is a disease specific questionnaire developed specifically for use in cancer. There are 5 functional scales physical, role, emotional, cognitive and social, a global health item, 3 symptom scales -fatigue, nausea/vomiting and pain, and single symptom items - dyspnea, appetite loss, constipation, diarrhea, and financial difficulties. All items are converted onto a 0 to 100 scale. With a total of 30 questions the instrument gives a broad and sensitive assessment of HRQoL in patients with cancer.

In order to compare the results of this questionnaire with the Italian data reported in Szende et al. [25], rather than mapping QLQ-C30 results onto EQ-5D to derive a single utility index, the model applies the scoring algorithm developed for QLQ-C30 [32] to EQ-5D raw numbers. In particular, we were interested in comparing "self-care" and "usual activities" domains of EQ-5D (Table VI), respectively, with "physical functioning" and "role functioning" subscales of QLQ-C30 of ASPIRE trial, as reported in Aaronson et al. [28].

In particular, from the trial emerged that even if point estimates tended to favor KRd, no statistically significant differences were observed between the $\mathrm{KRd}$ and $\mathrm{Rd}$ groups for the "physical functioning" and "role functioning" subscales. Similarly, for what concerns these subscales, changes from baseline within treatment groups were neither 
statistically nor clinically significant - with the exception of $\mathrm{Rd}$ at cycle 12 in physical functioning.

Given this, instead of defining treatment and subscale-specific levels of activity, we weighted all the "physical functioning" and "role functioning" scores reported in Stewart et al. [33] in order to obtain a single multiple myeloma-specific level of ability (69.28).

The survival curves presented in Figure 2 are taken from Jakubowiak et al. [34], where overall survival data from the ASPIRE trial have been extrapolated beyond the duration of the trial, by fitting a Weibull parametric distribution to real-world observational data from the US SEER registry.

Finally, gender-specific prevalence data of multiple myeloma in Italy were taken from the Italian Association of Cancer Registries (AIRTUM) [35].

Given these survival, demographic and health-related data, the model, applying the half-cycle correction, estimates treatmentspecific Societal costs of lost production and informal care (Table VII).

These results can be better explained with the support of the treatment-specific survival curves. Thanks to KRd, patients are expected to live longer: this implies less production lost for society and therefore a lower incremental burden for premature death per patients - in particular a saving of $22.94 \%$ with respect to Rd. However, this production is not completely restored for society because of the health-impairment of these individuals: these patients will not produce as their corresponding age- and gender-counterparts due to their reduced ability. Furthermore, because of their condition, they will need someone taking care of them.

From the point of view of society this means that those savings are partially offset by the costs related with reduced ability the society has to bear: reduced productivity and need for informal care.

Being premature death the foremost cost item - accounting for more of $50 \%$ of societal costs in both treatments - the overall effect is that KRd implies an absolute saving per patient of $€ 13,075$, equal to more than $7 \%$ savings.

\section{DISCUSSION}

Despite their often profound impact, both productivity costs and informal care are recurrently excluded from economic evaluations of healthcare interventions. This neglecting may be related to the lack of guidance and standardization in their measurement and valuation.

\begin{tabular}{lccc}
\hline \multirow{2}{*}{ Estimated outcomes } & \multicolumn{3}{c}{ Costs $(\boldsymbol{\ell} / \mathbf{p t s})$} \\
\cline { 2 - 4 } & KRd & $\mathbf{R d}$ & KRd - Rd \\
\hline Cost of premature death & 87,813 & 113,959 & $-26,146$ \\
Lost paid productivity for reduced ability & 19,397 & 17,406 & 1,991 \\
Lost unpaid productivity for reduced ability & 22,859 & 17,217 & 5,642 \\
Informal care for reduced ability & 21,913 & 16,474 & 5,439 \\
Total & $\mathbf{1 5 1 , 9 8 2}$ & $\mathbf{1 6 5 , 0 5 6}$ & $\mathbf{- 1 3 , 0 7 5}$ \\
\hline
\end{tabular}

Table VII. Example of model outcomes for the two treatment from the ASPIRE trial

We made an effort to come up with a comprehensive methodology. However, some limitations need to be observed. Our aim was to offer guidance and a practical method to estimate productivity costs and informal care for inclusion in economic evaluations, given the typical data availability from clinical studies.

Still, some assumptions may be considered too simplistic, such as applying average ageand gender-specific wage rates for the valuation of lost paid production. This, however, can be accounted for assessing the impact of diseases known to affect a particular social stratum; however, one needs to carefully assess the ethical implications of such a choice. As said, the model values lost paid production according to Human Capital approach. Yet, the valuation of health-related productivity changes in economic evaluations is extensively debated in the scientific literature [19]. An alternative approach to the Human Capital is the so-called Friction Cost approach $[36,37]$. This is based on the assumption that, given involuntary unemployment, an ill individual can eventually be replaced by a healthy worker. Hence, initial productivity levels can be restored after a "friction period".

Both because this approach is less straightforward to apply - it requires further assumptions and estimates of the length of the friction period - and because Human $\mathrm{Ca}$ pital is suggested in Capri et al. [15], the model estimates lost paid production according to this last approach.

In addition, the absence of a validated measurement instrument - such as the Health and Labor Questionnaire (HLQ) or the iMTA Productivity Cost Questionnaire (iPCQ) or the Valuation of Lost Productivity (VOLP) to collect data regarding both paid and unpaid production and informal care can be seen as a limitation. In fact, we are not claiming that the model may substitute well conducted empirical research, but we offer the possibility to obtain a well-informed and balanced estimate of such costs, starting from data that are generally available to researchers. 
For such reasons of convenience, uniformity and ease of use, the model relies on the data from the last available Italian TUS and from national health norms to define age- and gender-specific benchmarks. Then, it only needs survival, demographic and functionality data in order to estimate disease- and treatmentspecific estimates of lost production and informal care.

For what concerns HRQoL data, the model estimates the percentage difference from the population benchmark. In order to define age- and gender-specific population norms, for both production and self-care, we used the raw data of two - respectively "self-care" and "usual activities" - of the five domains of the EQ-5D as presented in Szende et al. [25]. Rather than relying on the single utility index as defined by EQ-5D and consequently taking into consideration the change in utility brought about by the disease/treatment, we decided to focus solely on the reduced ability to perform daily activities.

We believe that for estimating indirect costs and informal care, changes in physical impairment suit better than changes in utility, being this a wide concept, encompassing many aspects.

Another study involving estimates of the overall cost of disease and health problems has been performed in Spain [38]. In spite of methodological differences, our model and this exhibit common patterns with respect to losses due to premature mortality.

We did not have access to the same detailed data and therefore we were not able to replicate these results for Italy. We estimated the loss of paid production caused by premature death in Italy in 2015 , starting from the number of deaths and from the model estimates of the present value of future productivity.

In Spain in 2005, there were a total of 387,355

deaths and the loss of paid production caused by premature deaths has been estimated at $€$ 9,136 million. In Italy in 2015 , there were a total of 647,571 deaths [39] and the model estimate a $€ 26,998$ million loss of paid production caused by premature deaths.

The Gross Domestic Product (GDP) of Spain for 2005 amounted to $€ 908,792$ million. This means that paid production losses due to premature death were estimated to a figure equivalent to $1.01 \%$ of the GDP of Spain in 2005. The GDP of Italy for 2015 amounted to $€ 1,642,443$ million [40] and therefore paid production losses due to premature death amount to $1.58 \%$ of the GDP of Italy in 2015 , which is in line with the result for Spain.

There is also a heated debate in literature regarding the economic value of informal caregiving [41-44]. For instance in OlivaMoreno et al. [43] the total number of hours of informal care provided by main caregivers in Spain in 2008 was estimated at 4,193 million, while monetary valuation ranged from $€ 32,164$ million to $€ 53,299$ million using the proxy good method. Compared with the national GDP for 2008 the total value of informal cares ranged from $2.96 \%$ to $4.90 \%$ of the national GDP.

Once again we did not have access to the same detailed data and therefore we were not able to replicate the same methodology. Nonetheless, when we estimated the economic value of informal caregiving in Italy in 2015, starting from demographic data and TUS, the estimated total numbers of hours of informal care provided in Italy in 2015 was 7,954 million whose monetary evaluation amount to $€$ 77,713 million that represents the $4.73 \%$ of the Italian GDP in 2015.

\section{CONCLUSIONS}

Including costs of lost production and informal care in economic evaluations of healthcare interventions poses important methodological questions. These are often excluded from economic evaluations. Partly, this may be explained by the lack of a standardized methodology. Inclusion of productivity loss and informal care is important to accurately inform decision makers about the costs and potential savings of healthcare interventions. It is recommended, for evaluations conducted from the Societal perspective to not only include productivity loss related to paid work, but also that related to unpaid activities and informal care.

We developed a standardized model able to estimate the monetary value of the Societal burden for lost production and informal care of a population of known demographic composition, survival curve and ability status. This result will be useful for health economic analyses conducted from the perspective of the Italian society.

We encourage the inclusion of these costs in economic evaluations to allow decision makers to be fully informed about the costs and consequences of their decisions on healthcare interventions. 


\section{REFERENCES}

1. CIPE, Inter-Ministerial Committee for Economic Planning. Identifying criteria for contracting on the price of innovative medicines. Decree of January 30, 1997. Official Gazzette

2. Drummond MF, O’Brien B, Stoddart GL, et al. Methods for the Economic Evaluation in Health Care Programmes (2nd ed.). New York: Oxford University Press, 1997

3. Van Roijen L, Essink-Bot ML, Koopmanschap MA, et al. Labour and health status in economic evaluation of health care: The Health Labour Questionnaire. Int J Technol Assess Health Care 1996; 12: 405-15; https://doi.org/10.1017/ S0266462300009764

4. Jo C. Cost-of-illness studies: concepts, scopes, and methods. Clin Mol Hepatol 2014; 20: 327-37; https://doi. org/10.3350/cmh.2014.20.4.327

5. Colombo F, Llena-Nozal A, Mercier J, et al. Help wanted? Providing and paying for long-term care. Paris: OECD Publishing; 2011

6. Riedel M, Kraus M. Informal care provision in Europe: regulation and profile of providers. ENEPRI Research Report no. 96 (2011). Available at: https://www.ceps.eu/publications/informal-care-provision-europe-regulationand-profile-providers (last accessed December 2016)

7. Clark AM, Reid ME, Morrison CE, et al. The complex nature of informal care in homebased heart failure management. J Adv Nursing 2008; 61: 373-83; https://doi.org/10.1111/j.1365-2648.2007.04527.x

8. Knowlton AR, Arnsten JH, Gourevitch MN, et al. Microsocial environmental influences on highly active antiretroviral therapy outcomes among active injection drug users: The role of informal caregiving and household factors. JAIDS 2007; 46: S110-9; https://doi.org/10.1097/QAI.0b013e31815767f8

9. Clark RE, Xie H, Adachi-Mejia AM, et al. Substitution between formal and informal care for persons with severe mental illness and substance use disorders. J Ment Health Policy Econ 2001; 4: 123-32

10. Jiménez-Martin S, Prieto CV. The trade-off between formal and informal care in Spain. Eur J Health Econ 2012; 13: 461-90; https://doi.org/10.1007/s10198-011-0317-z

11. Weaver FM, Weaver BA. Does availability of informal care within the household impact hospitalisation? Health Econ Policy Law 2014; 9: 71-93

12. Krol M, Papenburg J, Koopmanschap M, et al. Do productivity costs matter? The impact of including productivity costs on the incremental costs of interventions targeted at depressive disorders. Pharmacoeconomics 2011; 29: 601-19

13. van den Berg B, Brouwer WB, Koopmanschap MA. Economic valuation of informal care. An overview of methods and applications. Eur J Health Econ 2004; 5: 36-45; https://doi.org/10.1007/s10198-003-0189-y

14. Hoefman RJ, van Exel J, Brouwer W. How to include informal care in economic evaluations. PharmacoEconomics 2013; 31: 1105-19; https://doi.org/10.1007/s40273-013-0104-z

15. Capri S, Ceci A, Terranova L, et al. Guidelines for economic evaluations in Italy: recommendations from the Italian group of pharmacoeconomic studies. Drug Inform J 2001; 35: 189-201; https://doi.org/10.1177/009286150103500122

16. Fattore G, Jommi C. La determinazione del prezzo dei farmaci innovativi in Italia registrati con procedura centralizzata europea. Mecosan 1997; 22: 103-11

17. Garattini L, Tediosi F, Ghislandi S, et al. How Do Italian Pharmacoeconomists Evaluate Indirect Costs? Value in Health 2000; 3: 270-6; https://doi.org/10.1046/j.1524-4733.2000.34004.x

18. Weisbrod BA. The valuation of human capital. J Polit Econ 1961; 69: 425-36; https://doi.org/10.1086/258535

19. Krol M, Brouwer W. How to estimate productivity costs in economic evaluations. Pharmacoeconomics 2014; 32: 335-44; https://doi.org/10.1007/s40273-014-0132-3

20. ISTAT - The National Institute for Statistics. Uso del tempo, 2012. Available at: http://www.istat.it/it/archivio/52079 (last accessed December 2016)

21. ISTAT - The National Institute for Statistics. Tavole di mortalità 2015. Available at: http://demo.istat.it/index.html (last accessed December 2016)

22. ISTAT - The National Institute for Statistics. Struttura delle retribuzioni, 2013. Available at: http://www.istat.it/it/ archivio/83362 (last accessed December 2016)

23. Associazione Domina. CCNL Domestico. Available at: http://www.colfdomina.it/ccnl/ (last accessed December 2016)

24. CNEL. La valorizzazione economica del lavoro volontario nel settore non profit, 2011. Available at: http://www. cnel.it/29?shadow_ultimi_aggiornamenti=3333 (last accessed December 2016) 
25. Szende A, Janssen B, Cabases J. Self-Reported Population Health: An International Perspective based on EQ-5D, 2014

26. The EuroQol Group. EuroQol, a new facility for the measurement of healthrelated quality of life. Health Policy 1990; 16: 199-208; https://doi.org/10.1016/0168-8510(90)90421-9

27. Stewart AK, Rajkumar SV, Dimopoulos MA, et al. Carfilzomib, lenalidomide, and dexamethasone for relapsed multiple myeloma. N Engl J Med 2015; 372: 142-52; https://doi.org/10.1056/NEJMoa1411321

28. Aaronson NK, Ahmedzai S, Bergman B, et al. The European Organization for Research and Treatment of Cancer QLQ-C30: a quality-of-life instrument for use in international clinical trials in oncology. J Natl Cancer Inst 1993; 85: 365-76; https://doi.org/10.1093/jnci/85.5.365

29. Kvam AK, Fayers PM, Wisloff F. Responsiveness and minimal important score differences in quality-of-life questionnaires: a comparison of the EORTC QLQ-C30 cancer-specific questionnaire to the generic utility questionnaires EQ-5D and 15D in patients with multiple myeloma. Eur J Haematol 2011; 87: 330-7; https://doi.org/10.1111/j.16000609.2011.01665.x

30. Leleu X, Petrucci MT, Welslau M, et al. Psychometric performance of the EORTC Quality of Life Core Questionnaire (QLQ-C30) and QLQ-Multiple Myeloma (QLQ-MY20) in relapsed/refractory multiple myeloma (RRMM). Blood 2013; 122: 1721

31. Wisløff F, Eika S, Hippe E, et al. Measurement of health related quality of life in multiple myeloma. Nordic Myeloma Study Group. Br J Haematol 1996; 92: 604-13; https://doi.org/10.1046/j.1365-2141.1996.352889.x

32. Fayers PM, Aaronson NK, Bjordal K, et al. The EORTC QLQ-C30 Scoring Manual (ed 3). Brussels: European Organisation for Research and Treatment of Cancer, 2001

33. Stewart AK, Dimopoulos MA, Masszi T, et al. Health-Related Quality of Life Results From the Open-Label, Randomized, Phase III ASPIRE Trial Evaluating Carfilzomib, Lenalidomide, and Dexamethasone Versus Lenalidomide and Dexamethasone in Patients With Relapsed Multiple Myeloma. J Clin Oncol 2016; 34: 3921-30; https://doi. org/10.1200/jco.2016.66.9648

34. Jakubowiak AJ, Campioni M, Benedict Á, et al. Cost-effectiveness of adding carfilzomib to lenalidomide and dexamethasone in relapsed multiple myeloma from a US perspective. J Med Econ 2016; 19: 1061-107; https://doi. org/10.1080/13696998.2016.1194278

35. AIRTUM ITACAN - Italian Association of Cancer Registries. Tumori in Italia, Versione 2.0. Available at: http:// Www.registri-tumori.it/ (last accessed December 2016)

36. Koopmanschap MA, Rutten FF, van Ineveld BM, et al. The friction cost method for measuring indirect costs of disease. J Health Econ 1995; 14: 171-89; https://doi.org/10.1016/0167-6296(94)00044-5

37. Koopmanschap MA, van Ineveld BM. Towards a new approach for estimating indirect costs of disease. Soc Sci Med 1992; 34: 1005-10; https://doi.org/10.1016/0277-9536(92)90131-9

38. Oliva-Moreno J. Loss of Labour Productivity Caused by Disease and Health Problems: What is the Magnitude of its Effect on Spain's Economy? Eur J Health Econ 2012; 13: 605-14; https://doi.org/10.1007/s10198-011-0344-9

39. ISTAT - The National Institute for Statistics. Bilancio demografico 2015. Available at: http://dati.istat.it/Index.aspx (last accessed December 2016)

40. ISTAT - The National Institute for Statistics. Principali aggregati del Prodotto interno lordo. Available at: http:// dati.istat.it/ (last accessed December 2016)

41. Chari AV, Engberg J, Ray KN, et al. The Opportunity Costs of Informal Elder-Care in the United States: New Estimates from the American Time Use Survey. Health Serv Res 2015; 50: 871-82

42. Arno PS, Levine C, Memmott MM. The economic value of informal caregiving. Health Aff (Millwood) 1999; 18: 182-8; https://doi.org/10.1377/hlthaff.18.2.182

43. Oliva-Moreno J, Pe-a-Longobardo LM, Vilaplana-Prieto C. An estimation of the value of informal care provided to dependent people in Spain. Appl Health Econ Health Policy 2015; 13: 223-31; https://doi.org/10.1007/s40258015-0161-X

44. Hollander MJ, Liu G, Chappell NL. Who Cares and How Much? The Imputed Economic Contribution to the Canadian Healthcare System of Middle-Aged and Older Unpaid Caregivers Providing Care to The Elderly. Healthc $Q$ 2009; 12: 42-9; https://doi.org/10.12927/hcq.2009.20660 